\title{
BREVE ESTUDO FILOSÓFICO SOBRE A ELABORAÇÃO DE CATEGORIAS EM REVISÕES DA LITERATURA: A PERSPECTIVA DA CIÊNCIA DA INFORMAÇÃO
}

Roberto Unger

\begin{abstract}
Resumo
Descreve, baseado na literatura, o saber prático da elaboração das categorias na construção das revisões de literatura e introduz a prática de uma explanação do saber teórico, baseado na Filosofia, para a elaboração das categorias. A categorização é utilizada como meio para apontar a que classe determinado conceito pertence considerando que não é um procedimento natural mas um esforço intelectivo de compreensão relacionado à síntese como método cognitivo que reúne e integra estudos agrupando o conhecimento em categorias facilitando a sua ordenação e sumarização. A compreensão do saber filosófico da elaboração de categorias nos estudos de revisão da literatura pode contribuir para reflexão e, posterior, aprimoramento dessa prática.
\end{abstract}

Palavras-chave: Categorias. Categorização. Ciência da informação. Revisão de literatura.

\section{Brief philosophical study on the elaboration of categories in literature reviews: the perspective of Information Science}

\begin{abstract}
It describes, based on the literature, the practical knowledge of the elaboration of categories in the construction of literature reviews and introduces the practice of an explanation of theoretical knowledge based on Philosophy for the elaboration of the categories. The categorization is used as a means to indicate to which class certain concept belongs considering it is not a natural procedure but an intellectual understanding effort related to the synthesis as a cognitive method that gathers and integrates studies grouping knowledge into categories facilitating their ordering and summarization. The understanding of the philosophical knowledge of the elaboration of categories in the studies of revision of the literature can contribute to reflection and, later, improvement of this practice.
\end{abstract}

Keywords: Categories. Categorization. Information Science. Literature review. 


\section{INTRODUÇÃO}

O método da construção das revisões da literatura utiliza a recuperação, a avaliação e a síntese da informação para atingir os resultados. Nesta construção, uma etapa de relevada importância é a categorização das evidências encontradas nos estudos. Elaborar as categorias costuma parecer uma atividade mecânica, embora cercada de extrema atenção e objetivo.

As categorias são tratadas pela Filosofia, ao longo dos tempos, como determinações da realidade servindo para compreender a própria realidade. Nosso breve estudo busca uma aproximação conceitual entre a prática da elaboração das revisões da literatura considerandoas como estoques de informação, os objetos de estudo da Ciência da Informação e a composição das categorias sob a perspectiva filosófica.

\section{REVISÃO DA LITERATURA E A CIÊNCIA DA INFORMAÇÃO}

Em uma interpretação da definição da Borko para a Ciência da Informação, Capurro e Bjorkland (2007, p. 185), afirmam que essa ciência tem como objeto a produção, a seleção, a organização, a interpretação, o armazenamento, a recuperação, a disseminação, a transformação e o uso da informação. O nosso estudo busca agregar a seleção, a organização e a interpretação da informação, alinhando-as com a síntese do conhecimento que é possibilitado pelas revisões de literatura. Para tanto é necessário uma aproximação com a metodologia da revisão integrativa da literatura e a sua concepção no que diz respeito à recuperação, a avaliação e a síntese do conhecimento produzido.

As revisões de literatura são dispositivos de informação que buscam agregar as informações existentes em determinados nichos do conhecimento produzido contribuindo para a construção de um novo corpo de conhecimento.

As revisões da literatura estão divididas em narrativas, integrativas, sistemáticas e meta analises. Estas englobam, cada uma, as suas especificidades e peculiaridades. As narrativas, por exemplo, permitem maior liberdade ao pesquisador, pois não exigem o rigor metodológico das demais revisões. A revisão integrativa permite a inclusão de estudos experimentais e não experimentais para uma completa compreensão do fenômeno analisado (SOUZA; SILVA; CARVALHO, 2010); a revisão sistemática é um tipo de investigação científica que tem por objetivo reunir, avaliar criticamente e conduzir uma síntese dos resultados de múltiplos estudos primários com o objetivo de responder a uma pergunta claramente formulada, utilizando métodos sistemáticos e explícitos para identificar, selecionar e avaliar as pesquisas relevantes, 
coletar e analisar dados de estudos incluídos na revisão; finalmente as meta analises são definidas como a análise estatística de uma coleção de resultados de estudos individuais, com o objetivo de integrar os resultados (CORDEIRO et al., 2007).

Comum a todos os tipos de revisão da literatura é a necessidade de responder a uma questão investigativa que norteia e delimita a sua metodologia de busca e recuperação da informação, de modo que, a mesma possa responder adequadamente ao objetivo proposto na pesquisa. Este método de pesquisa tem os mesmos critérios de uma pesquisa primária com relação a clareza da metodologia, o rigor científico e a possibilidade de replicação. A revisão da literatura delimita etapas metodológicas concisas e propicia utilização das evidências elucidadas em inúmeros estudos (COOPER, 1982).

\section{REVISÃO DA LITERATURA COMO SÍNTESE DA DISPERSÃO/ACUMULAÇÃO DA PRODUÇÃO DO CONHECIMENTO E TRANSMISSÃO DA INFORMAÇÃO}

Para o crescimento e aprimoramento da ciência é fundamental a organização e divulgação entre a sociedade do conhecimento oriundo das pesquisas científicas. A análise dos dados extraídos nos documentos (produção bibliográfica) se faz a partir da elaboração de categorias que têm significado específico e estritamente ligado às informações que se deseja obter. A síntese dos dados científicos de forma a criar instrumentos para a divulgação científica passa pelo método sistemático das revisões de literatura que permitem, pelo meio e uso de critérios específicos de estratégias de busca, localizar, recuperar, sintetizar e avaliar os achados.

Barreto (1994), concebe os "estoques estáticos de informação" como repositórios de conhecimento e que para que este repositório se realize, no âmbito da transferência da informação, deve existir uma ação de comunicação entre a fonte e o receptor. As revisões de literatura, deste modo, funcionam como catalizadores do conteúdo do conhecimento produzido em larga escala pelas diversas áreas do conhecimento.

\section{CATEGORIAS}

O primeiro significado atribuído às categorias é realista; elas são consideradas determinações da realidade e, em segundo lugar, noções que servem para indagar e compreender a própria realidade (ABBAGNANO, 2003).

Para Ramiz Galvão (1994), é na classe que se dividem as ideias ou termos; classe, série, atributo. Para Aristóteles as categorias são modos do ser, como substância, qualidade, 
quantidade, etc, pelos quais se formam os atributos do ser. Em ciências, as categorias correspondem à definição de atributos dos objetos para fins de classificação. Os sociólogos, por exemplo, buscaram reduzir a realidade social a algumas categorias básicas nas quais pudessem classificar as complexas manifestações do social (DICIONÁRIO, 1987, p. 161).

Kant (2001, B102, B103, p. 108-109), observa que a lógica geral abstrai do conteúdo do conhecimento as representações para que sejam apresentadas em conceitos. Ele entende que a síntese corresponde a um processo analítico, ou seja, o ato de juntar, umas às outras, diversas representações, concebendo o conhecimento.

É a síntese, de acordo com Kant, que reúne os elementos para os conhecimentos e os une em um determinado conteúdo, "a síntese pura, representada de uma maneira universal, dá o conceito puro do conhecimento".

O estudo de Chauí (2001, p. 79), sobre Kant descreve que o conjunto formado pela experiência, sensibilidade, percepção e entendimento transforma as percepções em conhecimentos intelectuais ou em conceitos. O entendimento, segundo Chauí, possui um conjunto de elementos que organizam os conceitos empíricos. Esses elementos são chamados de categorias. E sem as categorias não pode haver conhecimento intelectual.

A palavra categoria tem origem no latim "praedicamentum". Platão as chamou de "gêneros supremos", em grego significa "acusação". Ao longo da história e, em geral, referemse aos conceitos genéricos que podemos utilizar para elaborar e expressar pensamentos, juízos, julgamentos, etc. A categoria é simplesmente o predicado de uma proposição no entendimento de Aristóteles. Categorizar é apontar a que classe um determinado conceito pertence; não é um procedimento natural, mas um esforço intelectivo de compreensão. Criamos categorias na pesquisa científica com a intenção que os gregos emprestavam à epísteme: o processo de conhecer porque se quer conhecer e não de saber por acaso. A questão a ser responder ao se categorizar é: o que é isto que queremos investigar ou o que é isto com que nos deparamos no curso da investigação, nem porque sim, nem porque a tradição (THIRY-CHERQUES, 2012, p. 278-279).

As categorias organizam os dados da experiência de acordo com a qualidade, a quantidade, a causalidade, a finalidade, a verdade, a falsidade, a universalidade, a particularidade (CHAUÍ, 2001, p. 79).

Thiry-Cherques (2012, p. 55), afirma que as categorias não são ideias inatas, mas estão contidas nelas mesmas e são apenas logicamente necessárias ao conhecimento.

Não pretendemos neste estudo percorrer o caminho filosófico da categoria, não arregimentamos cabedal intelectual para esta empreitada, nossa pretensão é tão somente apontar 
um possível caminho que sinalize o emprego da técnica da análise dos textos científicos, a elaboração e construção das categorias com o intuito de sintetizar e organizar o conhecimento para posterior comunicação científica aos pares (transferência da informação).

\section{CATEGORIAS E EVIDÊNCIAS}

A categorização realizada na síntese dos estudos permite a compreensão do movimento da área, sua configuração, propensões teóricas metodológicas, análise crítica com indicação de tendências, recorrências e lacunas. Categorias identificam em cada texto e, no conjunto deles, as facetas nas quais o tema vem sendo analisado e estudado (VOSGERAU; ROMANOVSKI, 2014).

No contexto da elaboração das revisões da literatura, em um primeiro momento, o volume de evidências produzidas através das análises das categorias pode ser identificado como descontínuo e contraditório, mas à medida que se agrupam observa-se certa homogeneidade e que são determinadas pelos padrões de ocorrência.

As evidências, entre os estóicos e epicuristas, eram entendidas como critério de verdade. Não são fatos subjetivos, mas objetivos, não estão ligadas à clareza e à distinção das ideias, mas ao apresentar-se e manifestar-se de objeto (qualquer que seja) (ABBAGNANO, 2003).

Descartes (2003, p. 23) nos preceitos para a elaboração e construção do seu método determina que "[...] nunca aceitar coisa alguma como verdadeira sem que a conhecesse evidentemente como tal", evitando assim, a precipitação e a prevenção (os extremos!), e afastando a dúvida.

As evidências encontradas nos estudos de revisão são informações fruto dos resultados das pesquisas científicas designando a manifestação e apresentação do objeto / fenômeno analisado.

\section{A CONSTRUÇÃo dAs CATEgorias NO CAMPO DA REVISÃo DA LITERATURA}

Comum às revisões integrativas da literatura, a prática da síntese dos conhecimentos contidos nos estudos científicos deve obedecer a uma metodologia que permite integrar os principais conceitos dos estudos e categorizá-los de forma que se agrupem e deem sentido único à síntese. Nessa perspectiva, quando pensamos em reunir e integrar estudos, adotamos o método cognitivo da síntese que agrupa os conhecimentos em categorias. A prática envolve, pois, a 
identificação das informações necessárias ao objetivo da revisão e a organização das informações em categorias. Para Kant (op cit ABBAGNANO, 2003, p. 906), o método sintético é progressivo, pois é caracterizado [...] por produzir por si mesmo os elementos de suas construções.

A síntese, em nosso entendimento, inicia-se com a criação das categorias para facilitar a ordenação e sumarização das informações analisadas nos documentos científicos coletados. A dita categorização pode ser realizada de forma descritiva, em que o pesquisador indica os dados mais relevantes para seu estudo (BROOME, 2006).

$\mathrm{Na}$ organização da estratégia de busca é mister pensar nos critérios de inclusão e exclusão, eles devem ser nitidamente considerados para que o estudo e análise se coadunem com o propósito e objetivo delineados. Também é necessária uma construção meticulosa e criteriosa da estratégia de pesquisa, busca e recuperação da informação. Esse conjunto de atividades é imprescindível à organização da pesquisa. Consideramos a necessidade da elaboração de uma matriz metodológica de pesquisa bibliográfica, por nós definida como as atividades que compõem a estratégia de busca na pesquisa bibliográfica. Seu intuito é servir como base do método de pesquisa bibliográfica (information retrieval), para utilização em todas as bases de dados científicas. Tópicos de suma importância dizem respeito à utilização da linguagem natural e controlada na formulação das chaves de buscas.

As chaves de busca são dispositivos compostos e elaborados para a recuperação da informação nas bases de dados. A linguagem natural está contida no discurso técnico científico enquanto que a linguagem controlada está diretamente relacionada com os tesauros.

\section{AS FORMAS DE CATEGORIZAÇÃO NAS REVISÕES DA LITERATURA}

Os aportes sobre categorização na revisão da literatura estão presentes na literatura da metodologia e composição desse estoque de informação específico como demonstraremos a seguir. Os estudos encontrados dão conta da construção técnica das categorias, contudo não ensejam, de acordo com a nossa pesquisa para este trabalho, o saber filosófico contidos na sua urdidura.

Cooper (1982) cita Presby (1978), que observa: "[...] diferenças (em estudos) são canceladas no uso de categorias muito amplas, que leva à conclusão de que os resultados da pesquisa indicam diferenças insignificantes nos resultados" (tradução do autor).

Beyea e Nicoll (1998, p. 878), demonstram que a categorização começa na organização dos textos em pastas específicas, fazendo as anotações distintas de cada referência utilizada, é 
criada então uma grade que permite resumir as principais informações (evidências), de cada documento. Na organização final esta técnica auxilia na identificação nas lacunas de conhecimento ou pesquisa.

Whittemore e Knafl (2005), explicam que a categorização está presente, metodologicamente, na análise dos dados (ordenação, codificação e sumarização), na redução dos dados (que envolve a determinação de um sistema de classificação geral para o gerenciamento de dados de metodologias diversificadas) e na comparação dos dados (envolve um processo interativo de examinar as exibições de dados primários de origem para identificar padrões, temas ou relacionamentos). A categorização trabalhada dessa forma como garantem os autores, por meio de comparação e abordagem abrangentes facilitando a distinção de padrões, temas, variações e relacionamentos.

Para Pompeo, Rossi e Galvão (2009), categorização envolve a elaboração ou utilização de um instrumento de coleta de dados já validado que tem como objetivo extrair as informações chaves de cada documento analisado. O instrumento deve considerar itens como identificação do estudo, introdução e objetivos, características metodológicas, resultados e fatores relacionados encontrados.

Soares et al. (2014), propõem em seu estudo que a categorização, dentro do desenvolvimento da revisão da literatura, esteja presente na estratégia de análise e apresentação dos resultados, ordenando e sumarizando de modo a integrar as conclusões existentes.

\section{CATEGORIZAÇÃO, ORGANIZAÇÃO E REPRESENTAÇÃO DA INFORMAÇÃO}

Os estudos no campo da organização e representação da informação, notadamente Biblioteconomia e Ciência da Informação, está o "Postulado das categorias", que é o princípio normativo adotado para organizar um universo de assuntos, ou seja, um corpo de conhecimento sistematizado e organizado (CAMPOS, 2001).

A distinção de categorias na representação e organização da informação é utilizada por Shiyali Ramamrita Ranganathan, sendo aprimoradas com a apresentação da quarta edição da Colon Classification, em 1952, onde são definidas as cinco categorias fundamentais para a representação do conhecimento: P (Personalidade), M (Matéria), E (Energia), S (Space - local) e T (Time - época). A Colon Classification, organizada por Ranganathan, é construída baseada na "classificação facetada", que permite que a análise de um determinado assunto por facetas interprete suas diferentes manifestações e características (Barbosa, 1972, p. 76 apud ARAÚJO, 2006, p. 127). 
O termo "Categoria fundamental" é usado por Ranganathan para representar ideias fundamentais que permitem recortar um "universo de assunto" em classes bastante abrangentes, [...] são elas, as categorias, que fornecem a visão de conjunto dos agrupamentos que ocorrem na estrutura possibilitando o entendimento global da área (CAMPOS, 2001, p. 55).

Basicamente a partir dos trabalhos de Ranganathan outros estudiosos basearam seus estudos na Teoria da classificação facetada para a metodologia da composição de tesauros, teoria do conceito, estudo de montagem de bases de dados especializadas e automatizadas, a abordagem dos "boundary objects" no âmbito da teoria da classificação e representação do conhecimento, pesquisas em estruturas de classificação do conhecimento e etc.

Não trataremos nesse trabalho das particularidades dos desdobramentos das pesquisas e estudos que se seguiram a partir da elucidação e visão de Ranganathan.

Todavia, daremos limitado enfoque nas pesquisas de Ingetraut Dahlberg (1978) e Douglas Foskett (1996), e suas contribuições para a representação da informação baseadas em estudos sobre categorias.

Dahlberg explica a passagem do conceito para categoria a partir da concepção dos "elementos dos conceitos", ou seja, os conceitos se formam a partir dos enunciados sobre ele, onde cada enunciado contém elementos e características do conceito. Estabelece que, para a criação das categorias (facetas), deve-se considerar a reunião dos enunciados verdadeiros sobre os conceitos (ARAÚJO, 2006, p. 130).

Foskett estabelece que para a elaboração de um sistema de classificação facetado (por categorias) o estudo cuidadoso da literatura sobre o assunto, para determinar suas linhas gerais e o seu desenvolvimento, deve ser meticulosamente desempenhado; a análise do conteúdo do assunto e determinação de suas facetas; nas facetas, seguindo uma sequencia útil, a listagem dos focos que as compõem; determinação da ordem de citação (ordem de precedência ou prioridade das facetas), que é aplicada quando se faz a síntese para assuntos compostos; estudo da disposição das facetas dentro do esquema, que deverá mostrar claramente onde um assunto, simples ou composto, poderá ser encontrado (ARAÚJO, 2006, p. 128).

Como pode ser observado, na resumida descrição dos estudos, a noção de categoria para a análise de assuntos contidos em documentos é uma prática utilizada nos sistemas de classificação do conhecimento onde os arranjos das estruturas são desenhados para organizar e representar a informação de acordo com a síntese. 


\section{CONSIDERAÇÕES FINAIS}

Existe certa complexidade na (re) construção das categorias dispostas nos vários estudos, de forma que, na análise e síntese dos estudos estas tais categorias possam emergir baseadas e construídas nas similitudes cognitivas das estruturas dos documentos. Para tanto, durante a leitura crítica faz se necessária a compreensão daqueles elementos (categorias), que estabilizam e dão consistência ao raciocínio do autor do estudo analisado.

O raciocínio de Morin (2006, p. 15), estabelece que o conhecimento pertinente é o que é capaz de situar qualquer informação em seu contexto e, se possível, no conjunto em que está inscrita. Podemos dizer até que o conhecimento progride não tanto por sofisticação, formalização ou abstração, mas, principalmente pela capacidade de se contextualizar e se englobar.

Nossa reflexão se insere no contexto da tentativa da solução do problema da acumulação, distribuição e transferência da informação de maneira mais adequada. Existe um potencial nas revisões da literatura, que visa agregar volumes de informação contidas nos estoques de informação e que podem atender às demandas e necessidades de grupos específicos de usuários. $\mathrm{O}$ aporte da categorização das informações contidas nestes estoques não apenas contribui para a homogeneização do conhecimento científico produzido bem como auxilia também na oxigenação de estudos pretéritos. Criar categorias baseadas no estudo, avaliação e síntese do conhecimento é como poder manipular a disponibilidade e acesso à informação. 


\section{REFERENCIAS}

ABBAGNANO, Nicola. Dicionário de filosofia. São Paulo: Martins Fontes, 2003.

ARAÚJO, C. A. A. Fundamentos teóricos da classificação. Encontros Bibli: Revista Eletrônica de Biblioteconomia e Ciência da Informação, v. 11, n. 22, p. 117-140, 2006.

BARRETO, Aldo de Albuquerque. A questão da informação. São Paulo em perspectiva, v. 8, n. 4, 1994.

BEYEA, S. C.; NICOLL, L. H. Writing na integrative review. AORN Journal, v. 67, n. 4, p. $877878,19988$.

BROOME, M. E. Integrative literature reviews for the development of concepts. In: RODGERS, B. L.; CASTRO, A. A. Revisão sistemática e meta-análise. 2006. Disponível em: <www.metodologia.org/meta1.PDF>. Acesso em: 12 jan. 2011.

CAMPOS, M. L. A. Linguagem documentária: teorias que fundamentam sua elaboração. Niterói: EdUFF, 2001.

CAPURRO, Rafael; BJORKLAND, Birger. O conceito de informação. Perspectivas em Ciência da Informação, v. 12, n. 1, p. 148-207, 2007.

CHAUÍ, Marilena. Convite à filosofia. 12.ed. São Paulo: Ática, 2001.

COOPER, H. Scientific guidelines for conducting integrative literature reviews. Review of Educational Research, v. 52, n. 2, p. 291-302, 1982.

DESCARTES, René. Discurso do método. São Paulo: Martins Fontes, 2003.

DICIONÁRIO de ciências sociais. 2.ed. Rio de Janeiro: FGV, 1987.

GALVAO, Ramiz. Vocabulário etimológico, ortográfico e prosódico das palavras portuguesas derivadas da língua grega. Belo Horizonte: Garnier, 1994.

KANT, Immanuel. Crítica da razão pura. 5.ed. Lisboa: Fundação Calouste Gulbenkian, 2001.

MORIN, Edgar. A cabeça bem feita: repensar a reforma, reformar o pensamento. 12.ed. Rio de Janeiro: Bertrand Brasil, 2006.

POMPEO, D. A.; ROSSI, L. A.; GALVÃO, C. M. Revisão integrativa: etapa inicial do processo de validação de diagnóstico de enfermagem. Acta Paulista Enfermagem, v. 22, n. 4, p. 434438, 2009.

SOARES, C. B. et al. Revisão integrativa: conceitos e métodos utilizados na enfermagem. Revista da Escola de Enfermagem da USP, v. 48, n. 2, p. 335-345, 2014.

SOUZA, M. T.; SILVA, M. D.; CARVALHO, R. Revisão integrativa: o que é e como fazer. Einstein, v. 8, n. 1, pt. 1, p. 102-106, 2010. 
THIRY-CHERQUES, Hermano Roberto. Conceitos e definições: o significado em pesquisa aplicada nas ciências humanas e sociais. Rio de Janeiro: FGV, 2012.

VOSGERAU, D. S. R.; ROMANOVSKI, J. P. Estudos de revisão: implicações conceituais e metodológicas. Rev. Diálogo Educ., Curitiba, v. 14, n. 41, p. 165-189, jan./abr. 2014.

WHITTEMORE, R.; KNAFL, K. The integrative review: an updated methodology. Journal of advanced nursing, v. 52, n. 5, p. 546-552, 2005. 